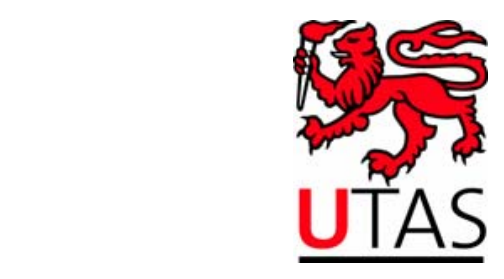

SCHOOL OF ECONOMICS AND FINANCE

Discussion Paper 2007-03

Teaching Aggregate Demand and Supply Models

Graeme Wells

ISSN 1443-8593

ISBN 978-1-86295-417-5 


\title{
Teaching Aggregate Demand and Supply Models
}

\author{
Graeme Wells* \\ University of Tasmania
}

September 32007

\begin{abstract}
This note analyses the inflation-targeting model that underlies recent textbook expositions of the Aggregate Demand-Aggregate Supply approach used in introductory courses in macroeconomics. The paper shows how numerical simulations of a model with inflation inertia can be used as a tool to help students understand adjustments in response to demand and supply shocks of various kinds.
\end{abstract}

*Thanks to Bruce Littleboy and Arusha Cooray for helpful comments. JEL classification numbers: A22, E31, E52. Correspondence: Graeme Wells, School of Economics and Finance, University of Tasmania, Private Bag 85, Hobart Tasmania, Australia 7005. email: graeme.wells@utas.edu.au fax +61362267587 


\section{Introduction}

David Romer (2000) has recently advocated changing the way aggregate demandaggregate supply (AD-AS) models are taught in undergraduate courses in macroeconomics. By re-casting the model from price-level, output space to a model in inflation, output space, students can quickly master tools with which to study macroeconomic policy issues in an environment where central banks have an inflation target and set monetary policy by means of a reaction function for the interest rate, rather than by controlling the money supply. Littleboy and Taylor (2006) and Bernanke, Olekalns and Frank (2005) have taken up this challenge in Australian textbooks aimed at beginning undergraduates.

I have used this model in teaching for both first-year and MBA students and have found that its immediate applicability to contemporary policy issues adds to its appeal among students. I have also developed a discrete-time model programmed in Excel which students can use to track dynamic adjustments in response to various types of shocks. The primary purpose of this note is to detail the model, describe its advantages for teaching introductory macroeconomics, and to provide illustrative simulations.

As well as providing students with an opportunity to easily conduct numerical exercises with the model, the algebraic illustration in this paper illustrates the important point that policy reaction functions must satisfy certain restrictions to ensure convergence to a stable equilibrium which achieves an inflation target, as well as an equilibrium in which output and the real interest rate at their natural levels.

The remainder of the note proceeds as follows. The next section begins by setting out the structure of the model, and using the resulting difference equations to analyse the effects of premanent and temporary demand and supply shocks. The third section provides some ullustrative numerical examples using the Excel model. Section 4 summarises. 


\section{The AD AS Model}

We consider a closed economy. The model follows the usual textbook notation, as follows (lower case roman letters other than $i$ and $r$ represent positive parameters and overbars indicate exogenous variables):

$\begin{array}{ll}Y & \text { GDP } \\ C & \text { Consumption } \\ I & \text { Investment } \\ G & \text { Government spending } \\ T & \text { Lump sum tax collections } \\ r & \text { Real interest rate } \\ i & \text { Nominal interest rate } \\ \pi & \text { Rate of inflation }\end{array}$

The equilibrium condition for goods-demand is the familiar IS curve which, as in (4), is an inverse relation between output and the real interest rate:

$$
\begin{aligned}
Y_{t} & =C_{t}+I_{t}+G_{t} \\
& =\left[\overline{C_{t}}+c\left(Y_{t}-\overline{T_{t}}\right)-a r_{t}\right]+\left[\overline{I_{t}}-b r_{t}\right]+\overline{G_{t}} \\
\text { which implies } Y_{t} & =\frac{1}{1-c}\left(\overline{C_{t}}-c \overline{T_{t}}+\overline{I_{t}}-(a+b) r_{t}\right) \\
& =\frac{\overline{E_{t}}}{1-c}-\frac{a+b}{1-c} r_{t}
\end{aligned}
$$

The symbol $\bar{E}$ incorporates the first three elements in the bracketed term of (3) which involve exogenous components of expenditure. The central bank is assumed to target the rate of inflation, with a reaction function which we write in terms of the real interest rate as

$$
r_{t}=\bar{r}+p \pi_{t}
$$

and, assuming static expectations so that $\pi_{t}=\pi_{t}^{e}$, the nominal interest rate is $i_{t}=r_{t}+\pi_{t}$. As will be shown below, the slope of the reaction function must be chosen to ensure stabilty, while the intercept term must be chosen so as to ensure that the equilibrium is $\left(r^{*}, \pi^{*}, Y^{*}\right)$ is achievable. 
In turn, it is assumed that full-employment output and the natural interest rate are exogenous and are denoted by $Y^{*}$ and $r^{*}$ respectively. The target rate of inflation is denoted $\pi^{* 1}$.

It is immediately clear that if the central bank is to achieve its inflation target, the parameters of the reaction function $\bar{r}$ and $p$ can not be chosen independently - they must be chosen so as to satisfy (6) and (7);

$$
\begin{aligned}
r^{*} & =\bar{r}+p \pi^{*} \\
\text { and } Y^{*} & =\frac{\bar{E}}{1-c}-\frac{a+b}{1-c} r *
\end{aligned}
$$

The aggregate demand (AD) curve is obtained by substituting the reaction function (5) into the IS relation (4), to give

$$
Y_{t}=\frac{\overline{E_{t}}}{1-c}-\frac{a+b}{1-c}\left(\bar{r}+p \pi_{t}\right)
$$

The relationship between the Keynesian-cross diagram and the AD curve is established by the fact that, for a given rate of inflation, a change in exogenous expenditure shifts the $\mathrm{AD}$ curve horizontally by an amount which depends on the size of the Keynesian multiplier. As a consequence, many of the exercises conducted in a Keynesian-cross diagram - the balanced-budget multiplier and the paradox of thrift, for example - can be replicated in terms of horizontal shifts of the AD curve. This close relationship between the Keynesian-cross diagram and the present $\mathrm{AD}$ curve emerges because, in effect, the real balance effect

\footnotetext{
${ }^{1}$ In Australian monetary policy the natural interest rate is often referred to as the "neutral rate'. For example, when appearing before a House Standing Committee in August 2006, then Governor Macfarlane said, in response to a question regarding the neutral interest rate, "I think when I was first asked this question I said that the real interest rate that had prevailed over the low-inflation period was about three per cent. If we were at $2 \frac{1}{2}$ per cent inflation, which is the average that you would hope that in the very long run you would come out at, that would give you a neutral rate of about $5 \frac{1}{2}$, plus or minus half a per cent for rounding error". (Macfarlane (2006), p.10-11). In terms of the notation in this paper, Governor Macfarlane's answer can be interpreted as saying that $i^{*}=r^{*}+\pi^{*}=0.03+0.025=0.055$. In a beginning macroeconomics course this (exogenous) natural interest rate can be motivated by appeal to small-open economy conditions with perfect capital mobility - in that case the natural rate is the exogenous world interest rate.
} 
has been assumed to be insignificant so that the only determinants of private spending are disposable income and the real interest rate. This approach offers a significant pedagogical advantage over the more usual IS-LM-AD structure in which the $\mathrm{AD}$ curve is represented in $(P, Y)$ space. In that case the relationship between the effects of changes in exogenous expenditures in the Keynesian cross and in the $\mathrm{AD}$ curve is complicated because, in the latter case, changes in the interest rate induced by the real balance effect must be taken into account.

Figure 1 illustrates diagrammatic elements of the model in long-run equilibrium at $\left(\pi^{*}, Y^{*}\right)$. The long run supply curve (LRAS) is vertical at $Y^{*}$; the short run supply curve (SRAS) is perfectly elastic at $\pi^{*}$; and the aggregate demand curve $(\mathrm{AD})$ is downward sloping. A permanent exogenous balancedbudget increase in spending, for instance, shifts the aggregate demand curve to the right by amount $\Delta \bar{G}$, inducing a positive output gap. Out of equilibrium, SRAS shifts vertically in response to the emergence of output gaps, leading to changes in the real interest rate and hence movements along the AD curve. In this example it can be seen that if equilibrium is to be restored at $\left(r^{*}, \pi^{*}, Y^{*}\right)$, the change in the reaction function parameter $\bar{r}$ must satisfy $\frac{\overline{\Delta E_{t}}}{1-c}=\frac{a+b}{1-c} \Delta \bar{r}$. 


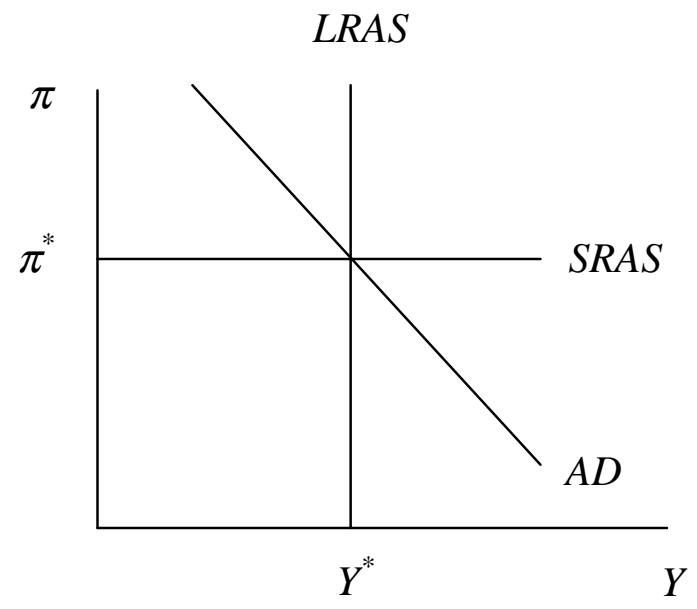

Figure 1 AD-AS Diagram

\subsection{Dynamics of inflation adjustment}

As Romer (2000) emphasises, a second advantage of the representation in $(\pi, Y)$ space is that it readily allows for the introduction of the distinction between short and longer-run supply responses. In the short run, firms' output supply is perfectly elastic with respect to the current rate of inflation; in the longer run, inflation (and hence real interest rates, via the central bank reaction function) adjust in autoregressive fashion in response to inflation shocks and the emergence of output gaps. Following the descriptive analysis of inertia in inflation adjustment in Romer (2000) and in subsequent textbooks, we write the vertical shifts in SRAS as a first-order process, with inflation increasing (with a oneperiod delay) in response to a Phillips curve (output gap) term $\left(Y-Y^{*}\right)$ and 
an exogenous inflation or supply shock, $\bar{s}$ :

$$
\pi_{t}=\pi_{t-1}+g\left(Y_{t-1}-Y^{*}\right)+s_{t-1}
$$

Although the ouput gap or Phillips curve component is written in absolute terms to preserve linearity this is not restrictive as, since $Y^{*}$ is constant, it can be normalised to unity without any loss of generality. Substituting the expression for IS and the reaction function into (9) gives a first order difference equation in $\pi$ :

$$
\begin{aligned}
\pi_{t} & =\pi_{t-1}+g\left(\frac{\bar{E}}{1-c}-\frac{a+b}{1-c} r_{t-1}-Y^{*}\right)+\bar{s}_{t-1} \\
& =\pi_{t-1}+g\left(\frac{\bar{E}}{1-c}-\frac{a+b}{1-c}\left[\bar{r}+p \pi_{t-1}\right]-Y^{*}\right)+\bar{s}_{t-1} \\
& =\left(1-g p \frac{a+b}{1-c}\right) \pi_{t-1}+g\left(\frac{\bar{E}}{1-c}-\frac{a+b}{1-c} \bar{r}-Y^{*}\right)+\bar{s}_{t-1}
\end{aligned}
$$

If the parameters of the reaction function have been chosen in accordance with (6) and (7), then (14) can be rewritten as

$$
\pi_{t}=\left(1-g p \frac{a+b}{1-c}\right) \pi_{t-1}+\pi^{*}+\bar{s}_{t-1}
$$

Hence, provided $0<\left(1-g p \frac{a+b}{1-c}\right)<1, \pi_{t}$ converges to a stable equilibrium provided $\bar{s}$ does. For $\bar{s}=0$ inflation converges to the target rate. The stability condition depends on a number of factors - the slope of the Phillips curve $(g)$; the sensitivity of private-sector expenditures to the real interest rate $(a$ and $b)$; the Keynesian multiplier $\left(\frac{1}{1-c}\right)$; and the slope of the policy reaction function $(p)$. Note that since $p$ is the only parameter chosen by policy makers, satisfaction of this stability requirement places an additional restriction, beyond (6) and (7), on the central bank reaction function. In turn, the dynamic adjustment of $Y$ is given by

$$
Y_{t}=\frac{\bar{E}_{t}}{1-c}-\frac{a+b}{1-c}\left(\bar{r}+p \pi_{t}\right)
$$

from which it follows that if $\pi_{t}$ converges to $\pi^{*}$ then $Y_{t}$ converges to $Y^{*}$. We now turn to consider dynamic adjustment of inflation and output to supply and demand shocks, drawing out important distinctions between permanent and temporary shocks. 


\subsection{Temporary demand shock}

Starting from the equilibrium illustrated in Figure 1, a temporary positive shock to aggregate demand (at time 0 ) means that $\bar{E}$ is temporarily greater than the value satisfying (6) and (7), or $\bar{E}_{0}>\bar{E}$ and $\bar{E}_{1}=\bar{E}$. In Figure 1, this shifts $\mathrm{AD}$ to the right for one period, after which it reverts to its original position ${ }^{2}$. This shock sets up a cyclical response in output: from (14) it initially rises by $\frac{\bar{E}_{0}-\bar{E}}{1-c}$, setting up an output gap of $\frac{\bar{E}_{0}-\bar{E}}{1-c}-Y^{*}$. The following period, the SRAS curve shifts up by $g\left(\frac{\bar{E}_{0}-\bar{E}}{1-c}-Y^{*}\right)$ increasing the real interest rate which, together with the fall in the exogenous component of demand, results in a short-run equilibrium level of output below $Y^{*}$. As illustrated in Figure 2, the negative output gap leads to a succession of falls in the inflation rate, and hence the interest rate, eventually restoring equilibrium at $\left(r^{*}, \pi^{*}, Y^{*}\right)$.

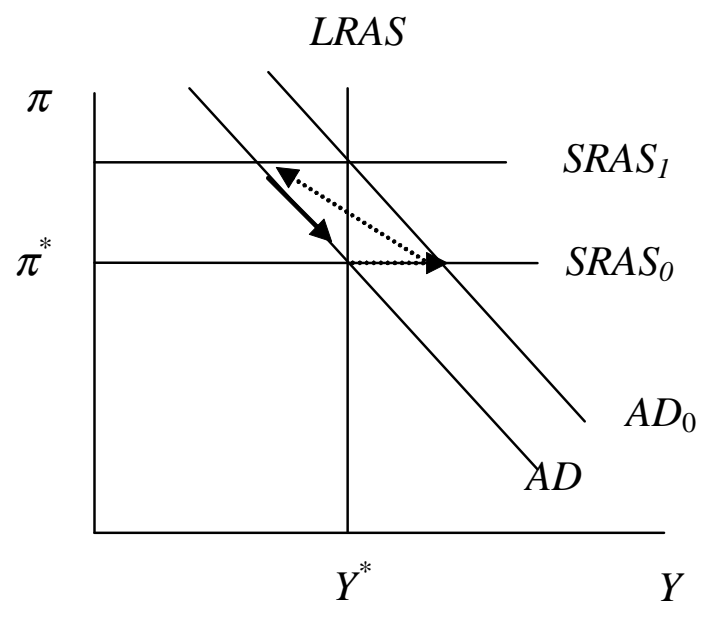

Figure 2 Cyclical response to demand shock

\footnotetext{
${ }^{2} \mathrm{~A}$ more complete analysis might incorporate a distinction between 'surprise' changes in demand, as is implicit here, and anticipated changes. In the latter case the central bank could avoid a recession by an appropriate sequence of $\bar{r}$.
} 


\subsection{Inflation shocks}

A once-only jump in the price level is modelled as a temporary inflation shock $s_{0}>0, s_{t}=0$ for $t>0$ while for a permanent inflation shock, $s_{t}>0$ for $t \geq 0^{3}$. In the present model with static expectations, the initial effect (shown in Figure 3 ) is the same in both cases. A positive inflation shock shifts SRAS upwards and leads to a negative output gap as the higher interest rate contracts demand. In the temporary case, the initial contraction in output is reversed in a series of steps as the inflation rate falls.

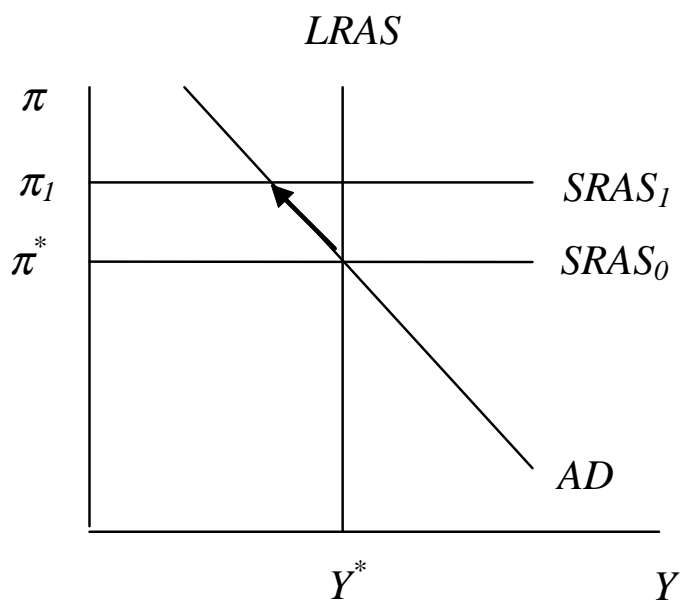

Figure 3 Initial response to price level and inflation shocks

There are two possibilities for the ongoing dynamics in the case of a permanent inflation shock, depending on the slope of the Phillips curve. If the Phillips curve is sufficiently steep, the disinflationary effect of the negative output gap may be large enough to more than offset the effect of the ongoing inflation shock. In that case, inflation converges to a long-run equilibrium value between

\footnotetext{
${ }^{3}$ A permanent inflation shock is difficult to motivate in the present closed economy model. In an open economy context, it could reflect a permanent change in world inflation.
} 
$\pi^{*}$ and $\pi_{1}$. If the Phillips curve is flat, the inflation rate converges to an equilibrium rate higher than $\pi_{1}$. These possibilities are illustrated using numerical simulations below.

\subsection{Identification}

Interestingly, the model can be used to illustrate a common identification problem in the estimation of central bank reaction functions. The approach originally followed by Taylor (1993) and Hooper, Bryant and Mann (1993) was not to econometrically estimate the reaction function; rather, they proposed a variety of policy rules and simulated the performance of the United States economy if the Federal Reserve had followed the proposed rules.

From the model, the nominal interest rate is given by

$$
\begin{aligned}
i_{t} & =r_{t}+\pi_{t}, \text { or } \\
i_{t} & =\left(\bar{r}+p \pi_{t}\right)+\pi_{t-1}+g\left(Y_{t-1}-Y^{*}\right)+\bar{s}_{t-1}
\end{aligned}
$$

Clearly, an econometrician estimating $(\mathrm{Y})$ would be in error if she were to infer that the estimated value of $g$ implied the inclusion of an output gap term in the bank reaction function. In $\mathrm{Y}$ the output gap appears in the reduced form for the interest rate from the impact of the Phillips curve on the actual rate of inflation, not because it appears in the reaction function. This general point is often overlooked in the empirical literature — de Brouwer and Gilbert (2005) provide a recent example for Australia.

\section{Simulations}

We now illustrate the preceding arguments with reference to numerical simulations, with parameter values as listed below ${ }^{4}$. Potential output has been

\footnotetext{
${ }^{4}$ The Excel spreadsheet which generated these simulations can be provided on request.
} 
normalised to unity ${ }^{5}$. Numerical values of the inflation shock are specified on a case-by-case basis. For the listed parameter values the stability condition is satisfied, since $0<\left(1-g p \frac{a+b}{1-c}\right)=0.25<1$. Parameter values have been chosen so that the interest-rate effect on investment is larger than for consumption; the budget is initially balanced; and the expenditure shares in GDP are plausible - for the long run equilibrium $\left(r^{*}, \pi^{*}, 1\right), C=0.6, I=0.2, G=0.2$. The monetary reaction function is such that a $1 \%$ increase in inflation increases the nominal interest rate by $1.25 \%$ or, in other words, it increases the real interest rate by $0.25 \%$.

Table 1 Numerical parameter values

$$
\begin{array}{ll}
C=\bar{C}+c(Y-\bar{T})-a r & =0.12+0.7 \cdot(Y-0.2)-2 r \\
I=\bar{I}-b r & =0.34-4 r \\
\bar{G} & =0.2 \\
r=\bar{r}+p \pi & =0.02875+0.25 \pi \\
\pi_{t}=\pi_{t-1}+g\left(Y_{t-1}-1\right)+\bar{s}_{t-1} & =\pi_{t-1}+0.15 \cdot\left(Y_{t-1}-1\right)+\bar{s}_{t-1} \\
r^{*} & =0.035 \\
\pi^{*} & =0.025
\end{array}
$$

A temporary demand shock is illustrated by a one-period temporary increase in $\bar{C}$ from 0.11 to 0.12 . As illustrated in Figure 2, this induces a one-period increase in output, followed by a fall in output below $Y^{*}$ and then a sequence of increasing values of output represented by movements down the AD curve as inflation and hence the real interest rate falls. For the given parameter values, convergence to $\left(r^{*}, \pi^{*}, 1\right)$ is rapid, as illustrated in Figure 4 . The spreadsheet can be used to support the more usual descriptive analysis by having students mark numerical values from the simulation as a sequence of points on 'curve-

\footnotetext{
${ }^{5}$ In 2006-07, Australian GDP is approximately $\$ 1000 \mathrm{~b}$, so for classroom discussion the units for GDP and its components can be thought of as $\$ 1000 \mathrm{~b}$.
} 
shifting' diagrams like Figure 2.

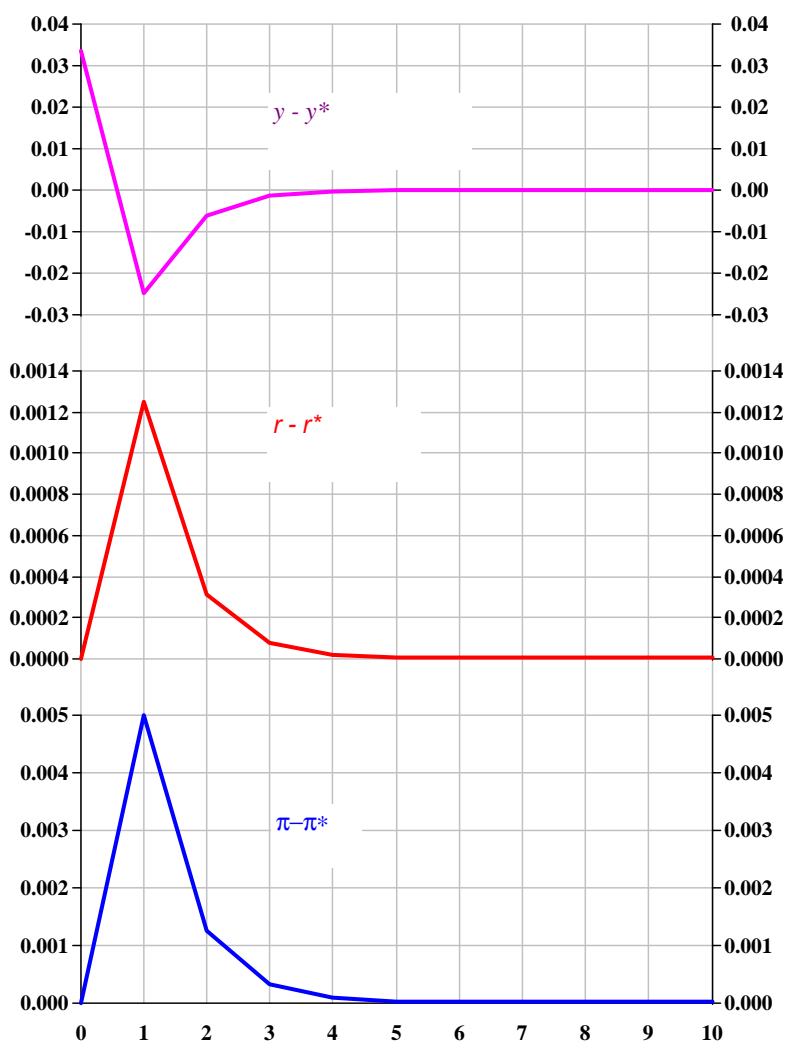

Figure 4 Response to temporary demand shock

Now consider the effect of price-level and inflation shocks. As outlined above, a permanent price level shock can be modelled as a once-only increase in $\bar{s}_{0}$; an inflation shock is a permanent increase in $\bar{s}_{t}$. We take these to be temporary and permanent increases of amount 0.01. Effects of the temporary shock are shown in Figure 5. By comparison with the demand shock, where the output effect precedes the inflation and interest-rate effect by one period, an inflation 
shock induces contemporaneous changes in the other variables.

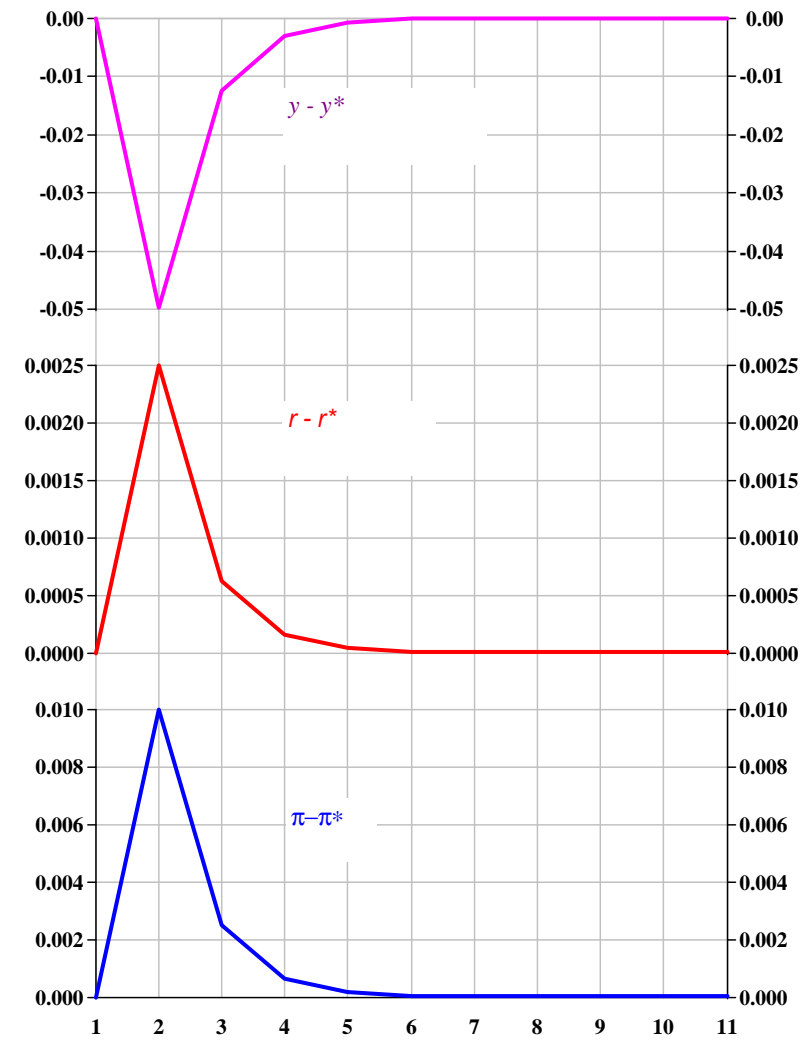

Figure 5 Response to temporary inflation shock

A permanent inflation shock illustrates the important proposition that the long-run equilibrium of the model is not necessarily $\left(r^{*}, \pi^{*}, 1\right)$. It also provides a useful illustration of the role of the slope of the Phillips curve in dynamic adjustment. To illustrate, we compare dynamics with $g=0.15$ (flat Phillips curve) and $g=0.35$ (steeper Phillips curve). All other parameter values are held fixed, ensuring dynamic stability in both cases, although with a steeper Philliups curve convergence is not monotonic. As illustrated in Figure 6, the model converges to an equilibrium in which a recessionary output gap is just sufficient 
to offset the ongoing effect of the inflation shock. Inspection of (13) shows that a flat Phillips curve implies more rapid convergence to equilibrium. Intuitively, a steeper Phillips curve implies that the output loss from a permanent inflation shock is smaller because there is less need for demand contraction to control inflation; this effect is illustrated in Figure 6 which shows that for a steeper Phillips curve long-run changes in output, the interest rate and inflation are all smaller than in the base case.

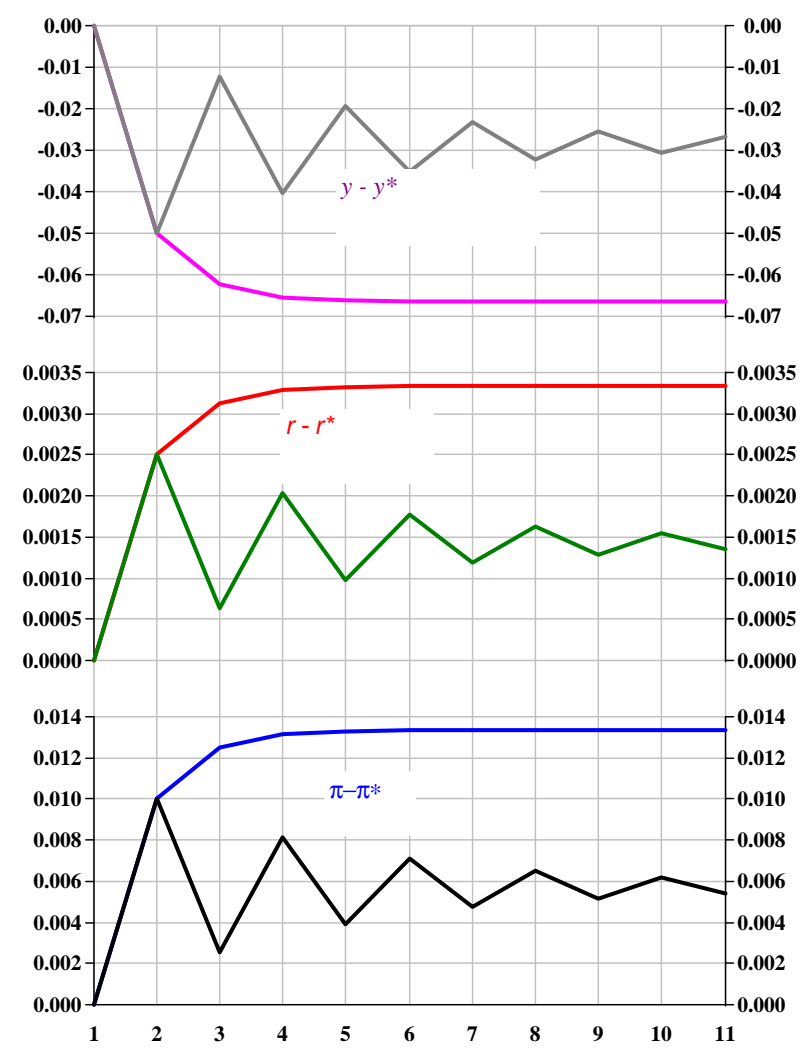

Figure 6 Responses to permanent inflation shock 


\section{Conclusion}

This note has shown that it is straightforward to provide a dynamic model of the inflation process underlying the aggregate demand and supply model that is starting to appear in introductory textbooks. The model has a Keynesian shortrun response and a 'classical' long-run response, and I have found that it can be used to engage student attention on current policy issues while at the same time expounding the basic short-run messages of the the Keynesian cross diagram. An explicit dynamic model has the advantage that, if an Excel spreadsheet is made available to students, they can undertake numerical simulations which illustrate dynamic responses to a variety of temporary and permanent shocks. Translating between the diagrams and numerical simulations is a useful teaching tool. For intermediate students, the model can also be used to illustrate the need for restrictions of the monetary reaction function, and to provide a useful example of identification issues in econometrics. While it is straightforward to extend the present approach to an open-economy model with a fixed nominal exchange rate, issues raised by a flexible exchange rate introduce additional

complexity best left for more advanced students. The same applies to modelling more realistic approaches to expectations-formation than the static-expectations model developed in this note.

\section{References}

[1] Bernanke, B.S., N. Olekalns, and R.H. Frank (2005). Principles of Macroeconomics. Sydney: McGraw-Hill.

[2] Bryant, R.C., P. Hooper and C.L. Mann (1993). Evaluating Policy Regimes. Washington DC: Brookings Institution.

[3] de Brouwer, G. and J. Gilbert (2005). 'Monetary Policy Reaction Functions in Australia'. Economic Record 81, June, 124-134. 
[4] Macfarlane, I. (2007). cited in report of the House Standing Committee, Review of the Reserve Bank Annual Report, 2006, Parliament of Australia, 25 May.

[5] Romer, D. (2000). 'Keynesian macroeconomics without the LM curve'. Journal of Economic Perspectives, Spring, 149-170.

[6] Taylor, J.B. (1993). 'Discretion versus policy rules in practice'. Carnegie Rochester Conference Series on Public Policy 39, 195-214. 


\section{School of Economics and Finance Discussion Papers}

2006-01

2006-02

2006-03

2006-04

2006-05

2006-06

2006-07

2006-08

2006-09

2006-10

2006-11

2005-01

2005-02

2005-03

2005-04

2005-05

2005-06

2005-07

2005-08

2005-09

2005-10

2005-11

2005-12

Estimates of Technology and Convergence: Simulation Results, Graeme Wells and Thanasis Stengos Dietary Pattern, Calorie Intake and Undernourishment: The Vietnamese Experience, Vinod Mishra and Ranjan Ray

Early Retirement in the Funding of Australian Retirement, Bruce Felmingham, Yong Hong Yan, Natalie Jackson and Maggie Walter

The Cyclical and Trend Behaviour of Australian Investment and Savings, Bruce Felmingham and Arusha Cooray Education and Child Labour: A Global Perspective, Ranjan Ray

A Regular Demand System with Commodity-Specific Demographic Effects, Paul Blacklow, Russell Cooper, Roger Ham and Keith McLaren

\section{Fertility Choices of Australian Couples, Paul Blacklow}

Is there Gender Bias in the Household's time Allocation in a Developing Country? The Indian Experience, Pushkar Maitra and Ranjan Ray

Examining Quality Distortion, Hugh Sibly

The Day-of-the-Week (DoW) Efficiency of the S\&P/ASX20 Index and it's Component Stocks

Nagaratnam Jeyasreedharan

Convergence to the Law of One Price: Evidence From Cross-Listed Chinese Stocks, Yong Hong Yan, Graeme Wells and Bruce Felmingham

Investment and Savings Cycles and Tests for Capital Market Integration, Arusha Cooray and Bruce Felmingham

The Efficiency of Emerging Stock Markets: Empirical Evidence from the South Asian Region, Arusha Cooray and Guneratne Wickremasinghe

Error-Correction Relationships Between High, Low and Consensus Prices, Nagaratnam Jeyasreedharan

Tests for RIP Among the G7 When Structural Breaks are Accommodated, Bruce Felmingham and Arusha Cooray

Alternative Approaches to Measuring Temporal Changes in Poverty with Application to India, Dipankor Coondoo, Amita Majumder, Geoffrey Lancaster and Ranjan Ray

Intertemporal Household Demographic Models for Cross Sectional Data, Paul Blacklow

Some Recent Evidences about the Global Integration of Chinese Share Markets, Yong Hong Yan and Bruce Felmingham

Managerial Objectives and Use Limits on Resource-Based Recreations, Hugh Sibly

The Feldstein-Horioka Model Re-Visted for African Countries, Arusha Cooray and Dipendra Sinha

Analysis of Changes in Food Consumption and their Implications for Food Security and Undernourishment: The Indian Experience in the 1900s, Ranjan Ray

An Extended Feldstein-Horioka Test for the Degree of Capital Mobility, Alexis Wadsley, Bruce Felmingham and Arusha Cooray

Extreme-Valued Distributional Relationships in Asset Prices, Nagaratnam Jeyasreedharan

Copies of the above mentioned papers and a list of previous years' papers are available on request from the Discussion Paper Coordinator, School of Economics and Finance, University of Tasmania, Private Bag 85, Hobart, Tasmania 7001, Australia. Alternatively they can be downloaded from our home site at http://www.utas.edu.au/ecofin 